\title{
ASSESSMENT OF ENVIRONMENTAL DETERMINANTS OF PHYSICAL ACTIVITY: A STUDY OF BUILT ENVIRONMENT INDICATORS IN BRNO, CZECH REPUBLIC
}

\author{
Zuzana Derflerová Brázdová1, Helena Klimusová2, Dalibor Hruška³, Alice Prokopová4, Aleš Burjanek ${ }^{5}$, Krauff \\ Rainer Schwanhaeuser Wulff' \\ 'Department of Public Health, Faculty of Medicine, Masaryk University, Brno, Czech Republic \\ ${ }^{2}$ Department of Psychology, Faculty of Arts, Masaryk University, Brno, Czech Republic \\ ${ }^{3}$ Department of Kinesiology, Faculty of Sports Studies, Masaryk University, Brno, Czech Republic \\ ${ }^{4}$ Department of Health Education, Faculty of Education, Masaryk University, Brno, Czech Republic \\ ${ }^{5}$ Department of Sociology, Faculty of Social Studies, Masaryk University, Brno, Czech Republic
}

\section{SUMMARY}

Background: Research on physical activity in relation to obesity gradually becomes more focused on environmental determinants, which can potentially influence people's health choices. The present article addresses the topic of physical activity from a wider sociological perspective. Our pilot study was designed with the objective of testing the applicability of a method included in the EC 6th Framework Programme EURO-PREVOB, in the Czech context. The method examines specific determinants of the built environment that can have an impact on physical activity at the population level. In addition, the study aims to analyze possible differences in built environment indicators and their relation to the physical activity of people living in neighbourhoods with areas of varying socioeconomic status.

Methods: The field study was carried out in the city of Brno, Czech Republic, in 5 neighbourhood quintiles, i.e. areas divided according to the socioeconomic status of local residents. In each quintile, we evaluated the quality of the built environment according to the quality, aesthetics and safety of segregated cycle facilities, playgrounds/playing areas, public open spaces, marked road crossings and pavements as well as signs of incivilities and devastation.

Results: Between the five quintiles, significant differences were found in the quality of parks and playgrounds/playing areas, pavements, marking of pedestrian crossings, and in general aesthetics, i.e. signs of incivilities and devastation of the built environment. No differences were found in the quality and use of cycle facilities.

Conclusions: The method we used for the evaluation of the built environment proved highly applicable in Czech populated areas. Monitoring of built environment indicators in the Czech Republic should provide a basis for health maps, showing potential associations between the prevalence of high-incidence, non-infectious diseases and various social determinants of physical activity. This information might help in achieving an improvement in these determinants at a community level and promoting an increase in physical activity at the population level.

Key words: social determinants, walking environment, cycle lanes, playground aesthetics, pavements

Address for correspondence: Z. Derflerová Brázdová, Department of Public Health, Faculty of Medicine, Masaryk University, Kamenice 5 , 62500 Brno, Czech Republic. E-mail: brazdova@muni.cz

\section{INTRODUCTION}

Recent publications on physical activity (PA) in relation to obesity prevention often mention environmental determinants as potential factors influencing people's healthy choices regarding both intentional and non-intentional PA(1-3). One of the principal social determinants is the built environment, which includes all man-made structures such as homes, schools, workplaces, parks and open-space recreation areas, playgrounds/playing areas, greenways, transportation systems, and motor vehicles (4). Recent research has provided substantial evidence for the link between the visual appeal of the built environment, population density, street connectivity, destination accessibility, walking and cycling environment, safety and aesthetics of playgrounds/playing areas, the quality and safety of pedestrian crossings and pavements, and the amount of PA at the community level (5-8). The same is also true for studies held in the Czech environment (9-11). Numerous studies have demonstrated that PA as a part of a healthy lifestyle is more common in people residing in neighbourhoods with high socioeconomic status (SES), and is associated with the quality of the built environment $(12,13)$. PA at the population level is affected, for example, by the density, number, safety and aesthetics of public transport stops. However, such factors have opposing effects in different communities: in high SES neighbourhoods, low number of bus/tram stops leads to an increase in car use; in low SES neighbourhoods, on the other hand, it results in more unintentional PA (14-16). Several findings have indicated that the safety and cleanliness of pavements and the quality of road crossings as well as the overall cleanliness of public spaces might increase the amount of PA as well. PA in children is unquestionably 
influenced by the pleasant appearance and safety of playgrounds (17-21). In contrast, traffic volume has been shown to be inversely related to the local residents' PA $(22,23)$. Still, it is often difficult to identify the indicators in the built environment that might be true causal factors of PA (24-27).

Keeping this issue in mind, our pilot study was designed to test the applicability of the method proposed by the EC 6th Framework Programme EURO-PREVOB in the Czech context. The method examines specific determinants of the built environment that can affect physical activity at the population level (28). The aim of the study was to analyze possible differences in indicators of the built environment and their relation to the PA of people living in neighbourhoods with areas of high and low SES.

\section{MATERIALS AND METHODS}

The study was conducted in spring 2012 in five community areas in Brno. The selection of territorial units (so-called "basic settlement units") was based on two sources. The first source was the 2001 census data from the city of Brno. A secondary analysis of the data file (which mapped educational characteristics of the population, unemployment figures, household amenities and the quality of the housing stock) allowed us to obtain the "index of socioeconomic status of the population" divided into five quintiles $(29,30)$.

The second source of our selection of territorial units in Brno entitled "Factor analysis - example of Brno" featured a study by Ondřej Mulíček that focused on internal socioeconomic differentiation in Brno (31). This study also relied on census data from 2001, and measured socioeconomic status of the residents of Brno, which combined educational and occupational characteristics of the population and was supplemented by data on household equipment, housing quality and the nature of the housing stock. This study also divided the "basic territorial units" of Brno into five quintiles. For EURO-PREVOB, and consequently for our ongoing study, sites were selected to represent each of the five quintiles of socioeconomic status (ranging from the highest to the lowest SES). Both sources showed an overlap.

The built environment in each of these neighbourhoods was evaluated according to the indicator criteria adopted from the
EURO-PREVOB project (32) conducted in 2008-2009, which was devoted, among other things, to designing an adequate assessment method. The method was tested in eleven countries, including the Czech Republic. In 2008, the areas selected for the EUROPREVOB project in Brno were supposed to be approximately $2.5 \mathrm{~km}^{2}$ each, i.e. ideally they would be squares with a side length of $1.6 \mathrm{~km}(28)$. For the cities assessed within the EURO-PREVOB project in France, Slovenia, Latvia, Turkey, Denmark etc. an area of $0.25 \mathrm{~km}^{2}$ was chosen. In our present study, the areas were reduced to $1 \mathrm{~km}^{2}$; the neighbourhoods, however, remained the same in terms of their location. Monitored sites with an area of $1 \mathrm{~km}^{2}$ were selected. By using street lines as boundaries, we approximated a relatively square shaped area. Inconsistencies, such as the quality of pedestrian crossings and public open spaces, occurred in cases where examined neighbourhoods were bordering quintiles that belonged to a different SES group, which prompted us to adjust the methodology for assessment of the built environment so that the examined area was reduced to $1 \mathrm{~km}^{2}$. This way, the obtained data would have greater homogeneity and thus greater validity (33).

The selection included traditionally settled areas around the historical city centre as well as more recent housing developments on the periphery. Communities living in these uptown areas differ from those residing in the city centre in visible attributes such as car (garage), dog and/or garden ownership.

In general, we analyzed the areas in the neighbourhoods where people live, spend their time, and through which they commute. We focused on the following indicators of environment quality: segregated cycle facilities (cycle lanes, cycle paths, shared-use paths etc.), parks and playgrounds/playing areas, safe pedestrian crossings, and visual appeal/degree of devastation of the built environment as a whole. The obtained data was subsequently assigned grades ranging from 1 to 4 to qualitatively describe the environment, with 1 and 4 being the best and worst quality, respectively (Figures 1-6). Direct observation and photographic documentation was used. The indicators were graded by two trained, independent observers, who received model sketches to use as templates for the grading (1 to 4). The observation and grading took place in the field and was led by the authors of the study, who were participants of the EURO-PREVOB project and have experience with the evaluation of monitored indicators. Observation and evaluation of the envi-

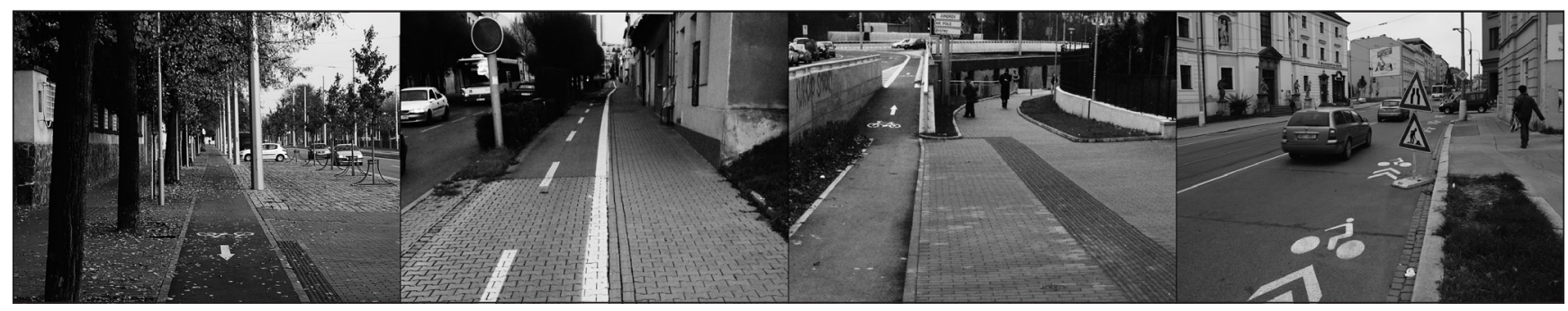

Fig. 1. Examples of classification of the quality of cycle facilities. (From the left, grading 1-4).

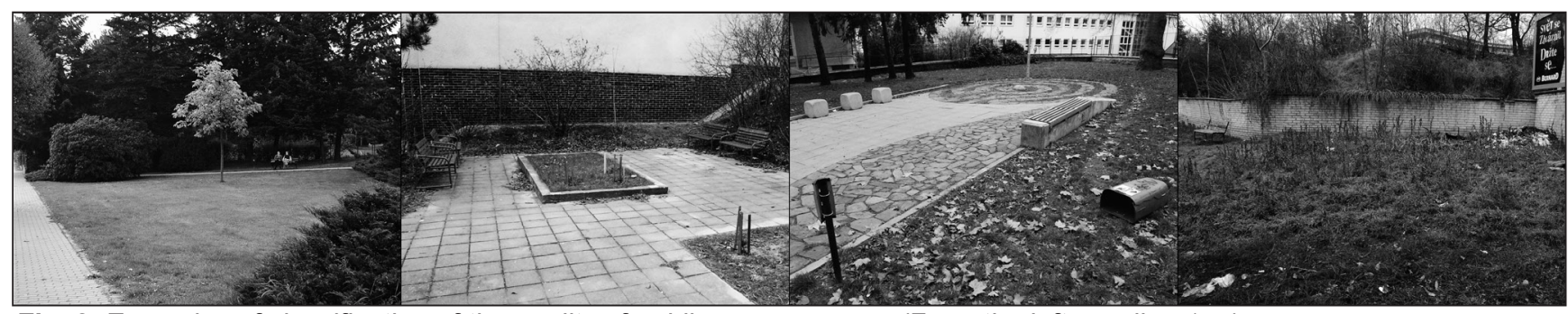

Fig. 2. Examples of classification of the quality of public open spaces. (From the left, grading 1-4). 


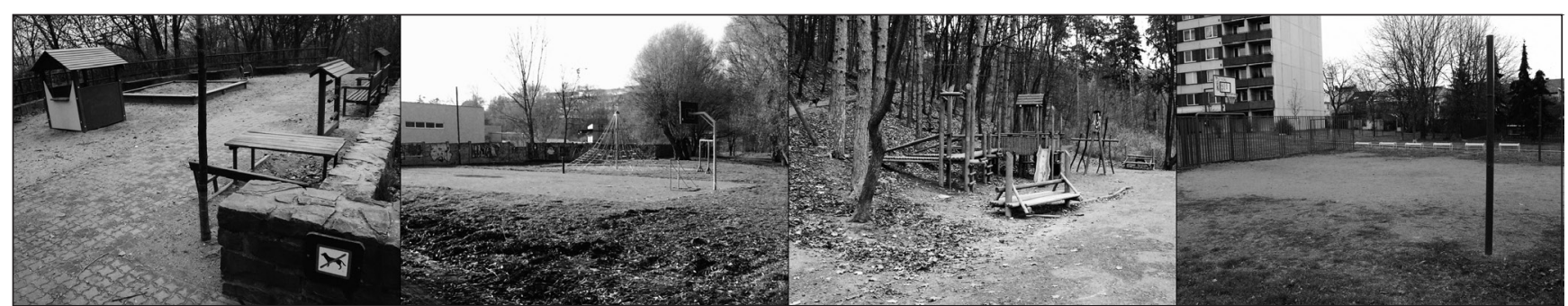

Fig. 3. Examples of classification of playgrounds/playing areas. (From the left, grading 1-4).

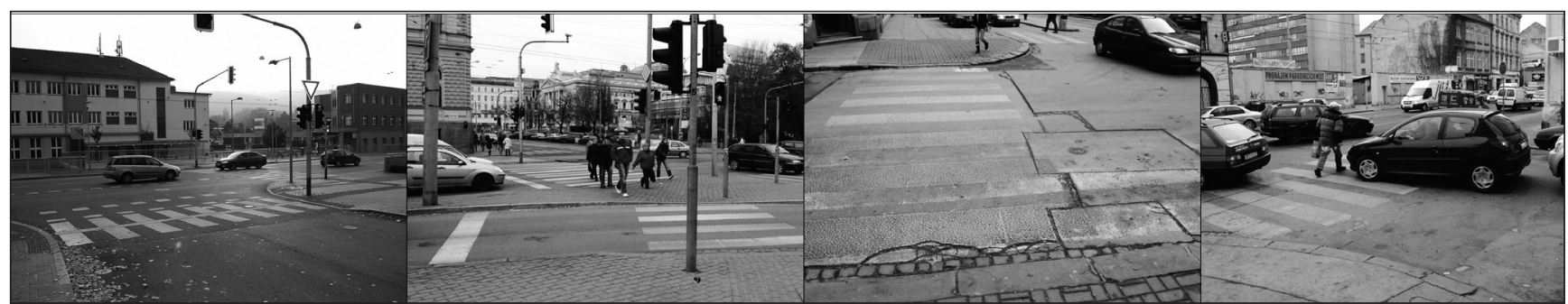

Fig. 4. Examples of classification of the quality of marked road crossings. (From the left, grading 1-4).

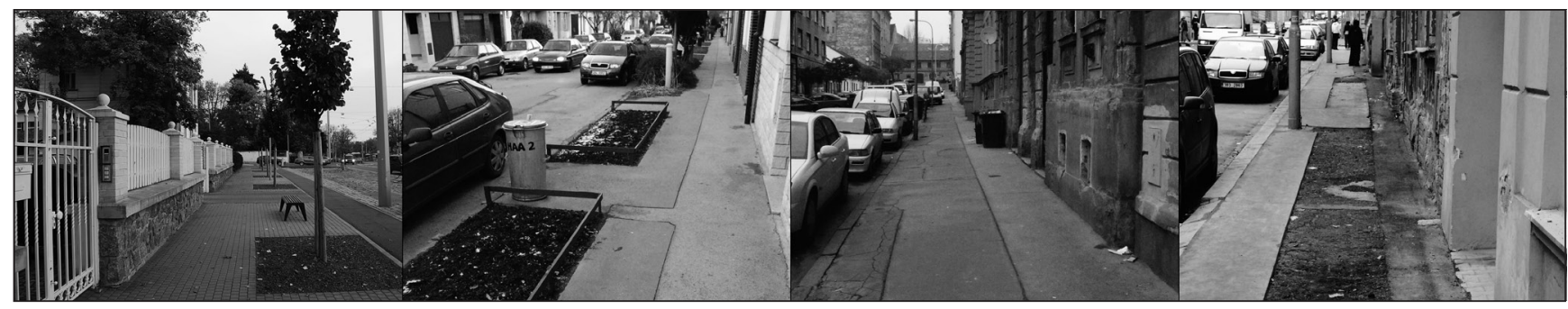

Fig. 5. Examples of classification of the quality of pavements. (From the left, grading 1-4).

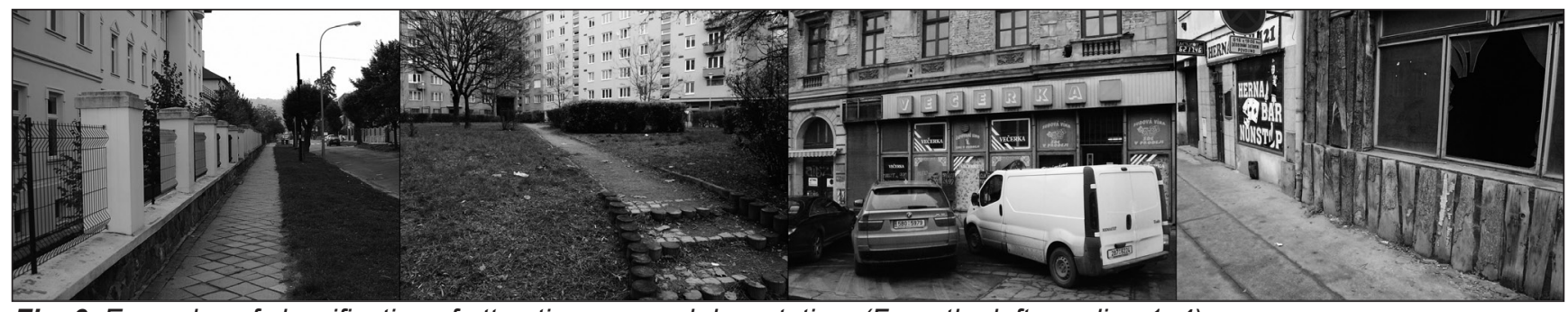

Fig. 6. Examples of classification of attractiveness and devastation. (From the left, grading 1-4).

ronment aesthetics was conducted so that primarily cleanliness, tidiness and usefulness would be taken into account. At the end of each observation day, the observers compared their results with each other and discussed the discrepancies to reach a consensus.

The following parameters were selected as potential factors determining the accessibility of PA for local residents: segregated cycle facilities (quality, length, obstructions and the level of bike traffic), public open spaces - especially parks and playing fields (cleanliness and maintenance, size, sports facilities and playgrounds), pedestrian crossings (safety and marking), pavements (quality, cleanliness and exclusive use by pedestrians), and overall appearance of the location (physical incivilities and degree of devastation).

Differences between the quintiles in terms of numbers of segregated cycle facilities, marked pedestrian crossings and playgrounds/playing fields, and the differences in the quality of individual indicators were tested using the Kruskal-Wallis test.

\section{RESULTS}

The differences in grading of the individual quality indicators of the built environment are shown in Tables 1-9.

\section{Cycle Facilities}

Differences in the numbers of segregated cycle facilities (lanes, paths, shared-use walkways, etc.) could not be statistically tested due to the generally low number of such facilities in each quintile. For the same reason, the quality and other attributes of cycle facilities could not be compared (Table 1).

Since cycle facilities in all five quintiles were completely passable and without obstructions, there were no differences to be tested (Table 2 and 4).

Differences in the use of the cycle facilities could not be tested due to insufficient data (Table 3 ).

\section{Public Open Spaces and Playgrounds/Playing Areas}

Differences could not be tested due to insufficient data (Table 5, 6).

Due to the ordinal scaling of indicator ratings (1 to 4), differences between the neighbourhood quintiles were analyzed using the Kruskal-Wallis test. The differences in the quality of public open spaces among the neighbourhood quintiles were statistically significant $(\mathrm{p}<0.01)$, with Quintiles 1 and 2 showing the highest quality, and Quintile 5 showing the poorest quality. A similar pattern was observed with playgrounds/playing areas $(\mathrm{p}<0.05)$. 
Table 1. Categorization (grading) of segregated cycle facilities

\begin{tabular}{|l|c|c|c|c|}
\hline \multirow{2}{*}{ Area } & \multicolumn{3}{|c|}{ Cycle facility category } & \multirow{2}{*}{ Total } \\
\cline { 2 - 4 } & $\mathbf{1}$ & $\mathbf{2}$ & $\mathbf{3}$ & \\
\hline Quintile 1 & 2 & 0 & 0 & 2 \\
\hline Quintile 2 & 1 & 0 & 0 & 1 \\
\hline Quintile 3 & 0 & 1 & 0 & 1 \\
\hline Quintile 4 & 2 & 1 & 1 & 4 \\
\hline Quintile 5 & 0 & 1 & 0 & 1 \\
\hline Total & 5 & 3 & 1 & 9 \\
\hline
\end{tabular}

Table 2. Passability and continuity of segregated cycle facilities

\begin{tabular}{|l|c|c|}
\hline \multirow{2}{*}{ Area } & Cycle facility continuity & \multirow{2}{*}{ Total } \\
\cline { 2 - 3 } & Yes & \\
\hline Quintile 1 & 2 & 2 \\
\hline Quintile 2 & 1 & 1 \\
\hline Quintile 3 & 1 & 1 \\
\hline Quintile 4 & 4 & 4 \\
\hline Quintile 5 & 1 & 1 \\
\hline Total & 9 & 9 \\
\hline
\end{tabular}

Table 3. Presence of cyclists on the path/lane (cycle traffic volume)

\begin{tabular}{|l|c|c|c|}
\hline \multirow{2}{*}{ Area } & \multicolumn{2}{|c|}{ Cyclists visible } & \multirow{2}{*}{ Total } \\
\cline { 2 - 3 } & No & Yes & \\
\hline Quintile 1 & 1 & 1 & 2 \\
\hline Quintile 2 & 0 & 1 & 1 \\
\hline Quintile 3 & 1 & 0 & 1 \\
\hline Quintile 4 & 3 & 1 & 4 \\
\hline Quintile 5 & 1 & 0 & 1 \\
\hline Total & 6 & 3 & 9 \\
\hline
\end{tabular}

Table 4. Obstructions on the cycle path/lane

\begin{tabular}{|l|c|c|c|}
\multirow{2}{*}{ Area } & \multicolumn{2}{|c|}{ Obstructions on the path/lane } & \multirow{2}{*}{ Total } \\
\cline { 2 - 3 } & No & Yes & \\
\hline Quintile 1 & 2 & 0 & 2 \\
\hline Quintile 2 & 1 & 0 & 1 \\
\hline Quintile 3 & 0 & 1 & 1 \\
\hline Quintile 4 & 3 & 1 & 4 \\
\hline Quintile 5 & 1 & 0 & 1 \\
\hline Total & 7 & 2 & 9 \\
\hline
\end{tabular}

\section{Pedestrian Crossings}

Due to the ordinal scaling of indicator ratings, differences in the quality of pedestrian crossings were analyzed using the Kruskal-Wallis test. Significant differences were observed between the quintiles $(\mathrm{p}<0.05)$. Crossings of the poorest quality were found in Quintile 5 $(\mathrm{md}=3.5)$; in all other quintiles, the quality was comparable (Table 7).
Table 5. Quality of public open spaces

\begin{tabular}{|l|c|c|c|c|}
\hline Area & $\mathbf{n}$ & Min. & Max. & Median \\
\hline Quintile 1 & 8 & 1 & 3 & 1.5 \\
\hline Quintile 2 & 14 & 1 & 3 & 2 \\
\hline Quintile 3 & 9 & 1 & 4 & 3 \\
\hline Quintile 4 & 11 & 2 & 4 & 3 \\
\hline Quintile 5 & 14 & 3 & 4 & 4 \\
\hline Total & 56 & 1 & 4 & 3 \\
\hline
\end{tabular}

$n-$ number of public open spaces in each quintile, Min. - minimum rating (highest grade), Max. - maximum rating (lowest grade)

Table 6. Quality of playgrounds/playing areas

\begin{tabular}{|l|c|c|c|c|}
\hline Area & $\mathbf{n}$ & Min. & Max. & Median \\
\hline Quintile 1 & 3 & 1 & 3 & 1 \\
\hline Quintile 2 & 7 & 1 & 3 & 1 \\
\hline Quintile 3 & 5 & 1 & 4 & 3 \\
\hline Quintile 4 & 9 & 2 & 4 & 3 \\
\hline Quintile 5 & 3 & 3 & 4 & 4 \\
\hline Total & 27 & 1 & 4 & 2 \\
\hline
\end{tabular}

$\mathrm{n}$-number of playgrounds/playing areas in each quintile, Min. - minimum rating (highest grade), Max. - maximum rating (lowest grade)

Table 7. Quality of pedestrian crossings

\begin{tabular}{|l|c|c|c|c|}
\hline Area & $\mathbf{n}$ & Min. & Max. & Median \\
\hline Quintile 1 & 27 & 1 & 4 & 2 \\
\hline Quintile 2 & 39 & 1 & 4 & 2 \\
\hline Quintile 3 & 62 & 1 & 4 & 2 \\
\hline Quintile 4 & 13 & 2 & 4 & 2 \\
\hline Quintile 5 & 48 & 1 & 4 & 3.5 \\
\hline Total & 189 & 1 & 4 & 2 \\
\hline
\end{tabular}

$\mathrm{n}$ - number of marked pedestrian crossings in each quintile, Min. - minimum rating (highest grade), Max. - maximum rating (lowest grade)

Table 8. Quality of pavements

\begin{tabular}{|l|c|c|c|c|}
\hline Area & $\mathbf{n}$ & Min. & Max. & Median \\
\hline Quintile 1 & 18 & 1 & 4 & 1.5 \\
\hline Quintile 2 & 8 & 1 & 4 & 1 \\
\hline Quintile 3 & 9 & 1 & 3 & 1 \\
\hline Quintile 4 & 16 & 1 & 4 & 3 \\
\hline Quintile 5 & 28 & 1 & 4 & 2.5 \\
\hline Total & 79 & 1 & 4 & 2 \\
\hline
\end{tabular}

$\mathrm{n}$ - number of pavements in each quintile, Min. - minimum rating (highest grade), Max. - maximum rating (lowest grade)

\section{Pavements}

Due to the ordinal scaling of indicator ratings, differences in the quality of pavements were analyzed using the Kruskal-Wallis test. Differences between the quintiles were significant $(\mathrm{p}<0.05)$ - quality of pavements was rated as highest SES in Quintiles 2 and 3, and as lowest SES in Quintile 4 (Table 8). 
Table 9. Tangible signs of unattractiveness

\begin{tabular}{|l|c|c|c|c|}
\hline Area & $\mathbf{n}$ & Min. & Max. & Median \\
\hline Quintile 1 & 3 & 2 & 2 & 2 \\
\hline Quintile 2 & 2 & 2 & 3 & 2.5 \\
\hline Quintile 3 & 2 & 3 & 3 & 3 \\
\hline Quintile 4 & 5 & 2 & 4 & 3 \\
\hline Quintile 5 & 14 & 2 & 4 & 4 \\
\hline Total & 26 & 2 & 4 & 3 \\
\hline
\end{tabular}

$\mathrm{n}$ - number of signs of unattractiveness in each quintile, Min. - minimum rating (highest grade), Max. - maximum rating (lowest grade)

Due to the ordinal scaling of indicator ratings, differences between the quintiles were tested using the Kruskal-Wallis test. Tangible unappealing features were least visible in Quintiles 1 and 2 and most visible in Quintile 5 (where they were also found in largest numbers). The differences were significant $(\mathrm{p}<0.01)$ (Table 9).

\section{DISCUSSION}

Segregated Cycle Facilities (Cycle Lanes, Cycle Paths)

Our assumption regarding this indicator in relation to the socioeconomic attributes of the residential area was that the density and/or length of cycle facilities would be greater in wealthier quintiles while in poorer neighbourhoods such facilities would be scarce or completely lacking (34). However, the results show that the relationship is very weak and does not seem causal. This is mainly because in the Czech Republic cycle facilities are not usually built due to the demand of residents living in the neighbourhood through which the path or lane leads. Rather, they are constructed in areas where terrain and local traffic solutions enable it or simply to provide a connection between other areas with cycle facilities, which may be required on various, sometimes merely political grounds. At present, the idea of cycle path construction or cycle lane marking on public demand does not seem realistic. Moreover, segregated cycle facilities (e.g. cycle lanes, cycle paths etc.) in the Czech Republic are traditionally viewed as leisure facilities rather than as a standard means of transport to school or workplace. For this reason, they are often built as shared-use paths or greenways in satellite towns and lead to open non-urban areas. Although their primary purpose is to provide an opportunity for cycling (and, in many cases, other activities, such as inline skating), it is cycling in the sense of "going for a ride" rather than "moving from one place to another". The presence of cycle paths in the built environment therefore mostly benefits intentional PA and does not really contribute to unintentional PA.

\section{Parks and Playgrounds/Playing Areas}

In contrast to the number and quality of segregated cycle facilities, which are not expected to be directly related to the SES of the neighbourhood, we assumed the quality of parks and playgrounds to be closely associated with the ranking of the quintiles $(19,35,36)$. Since parks and playgrounds serve important cultural and social functions, their appearance and quality are both influenced by the community life in the immediate proximity. However, observational support of this reasoning was not completely straightforward either, as appreciable differences were only found between the wealthiest Quintiles 1 and 2 and the poorest Quintile 5. Rather than going to public parks regularly, people living in single-family houses and villas often prefer to spend their outdoor time in their own gardens, or visit exclusive leisure facilities outside the neighbourhood (golf courses, playing fields, riding halls, tennis courts, etc.). On the other hand, parks are especially popular among the middle and lower social classes. SES of the neighbourhood is usually reflected in tangible signs of physical incivilities, for which parks and playgrounds literally serve as a case in point. From the economic perspective, parks and public playing grounds can be viewed as providing certain competition for commercial facilities such as fitness-centres and gyms. Dilapidation of public open spaces further diminishes the public's interest in their maintenance, and draws potential habitués to more attractive and upper-class places offering paid services.

\section{Pedestrian Crossings}

Marked and maintained road crossings complemented with traffic lights are significant indicators of the built environment. Safe traffic with a high degree of "walkability" reflects the quality of residential environments $(37,38)$. As stated by Frank et al., Giles-Corti and Donovan, and Marmot "the built environment interacts with the social environment, according to socioeconomic status; the lower the economic status, the lower the environment quality" (39-41). We expected better-quality and more attractive built environment in higher SES neighbourhoods compared to poorer ones. Somewhat more complicated is the issue of number/ density of road crossings. In higher SES residential areas, there is so little traffic that streets can be crossed relatively safely at any point. While the presence of marked pedestrian crossings certainly serves a protective function (pedestrians right-of-way), it is also restricting, as pedestrians cannot cross the road at any point anymore if there is a marked crossing nearby. This may create complications especially for the elderly, some of whom might have mobility problems, and for whom every additional metre of walking could become a source of discomfort. In our study, road crossings with the worst grading were those in Quintile 5; the other four quintiles did not differ significantly from each other.

\section{Pavements}

Pavements can be seen as an integral part of the built environment (42). Their quality, attractiveness and safety complement the overall quality of housing in the neighbourhood (43) and are crucial factors in PA such as jogging. In the Czech Republic, the quality of pavements is usually directly associated with the SES of local residents. Whereas pavements in the higher SES neighbourhoods are well-maintained and unoccupied by parked cars, which might take up a substantial part of the space originally intended for pedestrians, in the lowest SES neighbourhoods the situation is exactly the opposite. Pavements in rich neighbourhoods are neither covered with cigarette butts and litter nor animal excrements. In stark contrast, in the lowest SES neighbourhoods in the Czech Republic, pedestrians are often barely able to use the pavements at all, as they 
are occupied by parked cars to such an extent that people walking down the street are inevitably forced to brush their clothes against the cars. This observation applies predominantly to urban areas used primarily for housing, and is not valid for downtown areas and city centres where aesthetics is determined mainly by owners/ operators of office buildings and shops. We find it extremely likely that this issue has a negative impact on, for example, jogging or running opportunities in the vicinity of one's residence. Because of this, we consider pavements as one of the most significant quality indicators of the built environment in the present study, which has found significant differences in the quality of pavements in the five quintiles. It must be noted that the median grade in Quintile 1 was reduced due to ongoing road works, not incivilities.

\section{Overall Attractiveness, Physical Incivilities and Devastation}

Due to the political and social situation that was established in the 1950s and continued up until the early 1990s, the expression "good address" was not used so frequently in the Czech Republic - it only came to be used in the late 1990s. In spite of this, differences in the aesthetics of the built environment, whether they are appealing or showing visible signs of damage, are clearly visible between the various neighbourhoods. Damage can be caused either by intentional incivilities or poor maintenance by the members of the community who are indifferent to the community surroundings and fail to carry out immediate repairs when needed. On the contrary, an area visual appeal is typically a result of active striving for beautification of the built environment. We expected the appeal to increase with the SES of neighbourhood (44), although it must be mentioned that appeal in this respect should not be confused with tastefulness. Rather, what we mean by appeal is general neatness, functionality and cleanliness. Because we used features with a tangible lack of appeal as a measure of aesthetics in the present study, a rating of 1 was not included in the scale. In accordance with our expectations, differences between the quintiles were significant, with the highest degree of incivilities and disrepair found in Quintile 5.

With regard to our hypothesis on the dissimilarities between different SES neighbourhoods in terms of the quality of various indicators of the built environment, the greatest limitation of the employed methodology was probably the issue of quintile selection. In case of our survey, site selection was based on the results of two independent works, which categorized the Brno neighbourhoods based on an analysis of census data. Analyzed territorial units, so-called primary residential units, are relatively small and it was difficult to find homogeneous areas with the required dimensions. One thing to keep in mind is that in the "post-communist" countries, the built environment typically lacks a clear social and cultural structure to reflect visible and tangible attributes of sociologically structured neighbourhoods. In such neighbourhoods, the built environment is understandably shaped mainly by social phenomena characteristic of low-income groups. This fact, in turn, may reflect the extent to which opportunities for PA are used by the local residents. Decreased attractiveness of playing areas and public open spaces, signs of vandalism, etc., might drive away even those residents (and their children) who would otherwise be interested in using open spaces for exercise and other physical activity.
It is important to clarify that our results are objective observations that cannot be compared with data obtained through subjective measures such as questionnaires, which are used for the measurement of the public's perceptions and evaluations of individual indicators of the built environment $(11,45)$. Subjective assessment might be inconsistent for various reasons, for example, obese individuals might perceive the level of pedestrian friendliness of various areas in the neighbourhood differently from individuals who are physically fit $(23,24)$. Thus, objective assessment of the built environment will always serve as a useful complement to subjective measures. The more objective data used (e.g. census, GIS, unemployment statistics etc.), the greater the relevance of the evaluation of neighbourhood quality.

\section{Limitations}

In terms of international comparability the most important limit for the study is the selection of monitored sites, as described above. The natural limit of site selection (and consequently of our study) is the fact that the highest SES quintile as well as the lowest one will always differ from country to country.

\section{CONCLUSIONS}

Modifying the EURO-PREVOB methodology $\left(1.0 \mathrm{~km}^{2}\right.$ instead of $2.5 \mathrm{~km}^{2}$ quintile size) when assessing built environment indicators in Brno proved to be more accurate and appropriate for practical use.

In the event that the census data is of limited suitability, it is possible to abandon the SES quintile categorization completely in further research and study the indicators of the built environment independently of this categorization. Since the information value of individual indicators differs - for example, cycle facilities are influenced by factors other than pavements and playgrounds it is necessary to select indicators carefully with respect to the research question so that the answers obtained are truly relevant to the topic of interest.

Documentation of the built environment indicators in relation to a population's PA should serve as a starting point for the construction of public health community maps, which are good tools for monitoring potential associations between the prevalence of high-incidence non-infectious diseases and various social determinants of PA. This information could be used for further improvement of these determinants at a community level, which, in turn, might help increase physical activity at the population level.

\section{Acknowledgements}

The field part of the study was conducted using the method outlined in the EURO-PREVOB project funded by the European Commission 6th Framework Programme (Project No. 044291). Data analyses were performed with the institutional support of Masaryk University.

\section{Conflict of Interest}

None declared 


\section{REFERENCES}

1. Adams MA, Sallis JF, Kerr J, Conway TL, Saelens BE, Frank LD, et al. Neighborhood environment profiles related to physical activity and weight status: a latent profile analysis. Prev Med. 2011 May;52(5):326-31.

2. Boone-Heinonen J, Evenson KR, Song Y, Gordon-Larsen P. Built and socioeconomic environments: patterning and associations with physical activity in U.S. adolescents. Int J Behav Nutr Phys Act. 2010 May 20;7:45. doi: 10.1186/1479-5868-7-45.

3. Cutts BB, Darby KJ, Boone CG, Brewis A. City structure, obesity, and environmental justice: an integrated analysis of physical and social barriers to walkable streets and park access. Soc Sci Med. 2009 Nov;69(9):131422.

4. Sallis JF. Measuring physical activity environments: a brief history. Am J Prev Med. 2009 Apr;36(4 Suppl):S86-92.

5. Berrigan D, Pickle LW, Dill J. Associations between street connectivity and active transportation. Int J Health Geogr. 2010 Apr 23;9:20. doi: 10.1186/1476-072X-9-20.

6. Durand CP, Andalib M, Dunton GF, Wolch J, Pentz MA. A systematic review of built environment factors related to physical activity and obesity risk: implications for smart growth urban planning. Obes Rev. 2011 May;12(5):e173-82.

7. Kerr J, Norman GJ, Adams MA, Ryan S, Frank L, Sallis JF, et al. Do neighborhood environments moderate the effect of physical activity lifestyle interventions in adults? Health Place. 2010 Sep;16(5):903-8.

8. Kwaśniewska M, Kaleta D, Dziankowska-Zaborszczyk E, Drygas W. Healthy behaviours, lifestyle patterns and sociodemographic determinants of the metabolic syndrome. Cent Eur J Public Health. 2009 Mar;17(1):14-9.

9. Dragano N, Bobak M, Wege N, Peasey A, Verde PE, Kubinova R, et al. Neighbourhood socioeconomic status and cardiovascular risk factors: a multilevel analysis of nine cities in the Czech Republic and Germany. BMC Public Health. 2007 Sep 21;7:255-66.

10. Sigmundová D, El Ansari W, Sigmund E. Neighbourhood environment correlates of physical activity: a study of eight Czech regional towns. Int J Environ Res Public Health. 2011 Feb;8(2):341-57.

11. Sofková T, Přidalová M, Mitáš J, Pelclová J. The level of neighborhood walkability in a place of residence and its effect on body composition in obese and overweight women. Cent Eur J Public Health. 2013 Dec;21(4):184-9.

12. McNeill LH, Kreuter MW, Subramanian SV. Social environment and physical activity: a review of concepts and evidence. Soc Sci Med. 2006 Aug;63(4):1011-22.

13. Renalds A, Smith TH, Hale PJ. A systematic review of built environment and health. Fam Community Health. 2010 Jan-Mar;33(1):68-78.

14. Fitzhugh EC, Bassett DR Jr, Evans MF. Urban trails and physical activity: a natural experiment. Am J Prev Med. 2010 Sep;39(3):259-62.

15. Troped PJ, Wilson JS, Matthews CE, Cromley EK, Melly SJ. The built environment and location-based physical activity. Am J Prev Med. 2010 Apr;38(4):429-38.

16. Winters M, Brauer M, Setton EM, Teschke K. Built environment influences on healthy transportation choices: bicycling versus driving. J Urban Health. 2010 Dec;87(6):969-93.

17. Cosco NG, Moore RC, Islam MZ. Behavior mapping: a method for linking preschool physical activity and outdoor design. Med Sci Sports Exerc. 2010 Mar;42(3):513-9.

18. Galvez MP, Pearl M, Yen IH. Childhood obesity and the built environment. Curr Opin Pediatr. 2010 Apr;22(2):202-7.

19. Grow HM, Cook AJ, Arterburn DE, Saelens BE, Drewnowski A, Lozano P. Child obesity associated with social disadvantage of children's neighborhoods. Soc Sci Med. 2010 Aug;71(3):584-91.

20. Potestio ML, Patel AB, Powell CD, McNeil DA, Jacobson RD, McLaren L. Is there an association between spatial access to parks/green space and childhood overweight/obesity in Calgary, Canada? Int J Behav Nutr Phys Act. 2009 Nov 20;6:77. doi: 10.1186/1479-5868-6-77.

21. Sandercock G, Angus C, Barton J. Physical activity levels of children living in different built environments. Prev Med. 2010 Apr;50(4):193-8.

22. Marshall JD, Brauer M, Frank LD. Healthy neighborhoods: walkability and air pollution. Environ Health Perspect. 2009 Nov;117(11):1752-9.

23. Elinder LS, Jansson M. Obesogenic environments - aspects on measurement and indicators. Public Health Nutr. 2009 Mar;12(3):307-15.
24. Hoehner CM, Brennan Ramirez LK, Elliott MB, Handy SL, Brownson RC. Perceived and objective environmental measures and physical activity among urban adults. Am J Prev Med. 2005 Feb;28(2 Suppl 2):105-16.

25. Keast EM, Carlson NE, Chapman NJ, Michael YL. Using built environmental observation tools: comparing two methods of creating a measure of the built environment. Am J Health Promot. 2010 May-Jun;24(5):354-61.

26. McKinnon RA, Reedy J, Handy SL, Rodgers AB. Measuring the food and physical activity environments: shaping the research agenda. Am J Prev Med. 2009 Apr;36(4 Suppl):S81-5.

27. Wong F, Stevens D, O'Connor-Duffany K, Siegel K, Gao Y; Community Interventions for Health $(\mathrm{CIH})$ collaboration. Community Health Environment Scan Survey (CHESS): a novel tool that captures the impact of the built environment on lifestyle factors. Glob Health Action. 2011 Mar 7;4:5276. doi: 10.3402/gha.v4i0.5276.

28. Derflerová Brázdová Z, Schwanhaeuser K, Sekot A, Hruška D, Sebera M. EURO-PREVOB: project report on cooperation of Masaryk University as a representative of Czech republic in the 6th Framework programme No. 044291. Výživa a potraviny. 2012;Suppl 1:1-12. (In Czech.)

29. Sochorová R. Patterns of spatial exclusion in Brno in the year 2001 in comparison with the year 1991 [dissertation] [Internet]. Brno: Masaryk University, Faculty of Social Studies; 2007 [cited 2015 Nov 18]. Available from: https://is.muni.cz/th/52217/fss_m/Sochorova_-_Vzorce_ prostorove_exkluze.pdf. (In Czech.)

30. Burjanek A. Area selection for a pilot study in Brno. Výživa a potraviny. 2012;Suppl 1:37-9. (In Czech.)

31. Mulíček O. Factorial analysis of segregation - the case of Brno. In: Prevention of space segregation. Prague: Ministry of Regional Development; 2005. p. 60-70. (In Czech.)

32. Pomerleau J, Knai C, Foster C, Rutter H, Darmon N, Derflerová Brázdová $\mathrm{Z}$, et al. Measuring the food and built environments in urban centres: reliability and validity of the EURO-PREVOB Community Questionnaire. Public Health. 2013 Mar;127(3):259-67.

33. Hruška D. EURO-PREVOB: The collection of data describing food and built environment. Výživa a potraviny. 2012;Suppl 1:13-36. (In Czech.)

34. Hoedl S, Titze S, Oja P. The bikeability and walkability evaluation table reliability and application. Am J Prev Med. 2010 Nov;39(5):457-9.

35. Boone-Heinonen J, Gordon-Larsen P. Life stage and sex specificity in relationships between the built and socioeconomic environments and physical activity. J Epidemiol Community Health. 2011 Oct;65(10):847-52.

36. Parra DC, Gomez LF, Fleischer NL, David Pinzon J. Built environment characteristics and perceived active park use among older adults: results from a multilevel study in Bogotá. Health Place. 2010 Nov;16(6):1174-81.

37. Frank L, Kavage S. A national plan for physical activity: the enabling role of the built environment. J Phys Act Health. 2009 Nov;6 Suppl 2:S186-95.

38. McCarron DA, Richartz N, Brigham S, White MK, Klein SP, Kessel SS. Community-based priorities for improving nutrition and physical activity in childhood. Pediatrics. 2010 Nov;126 Suppl 2:S73-89.

39. Frank L, Kavage S, Devlin A. Health and the built environment: a review. Canadian Medical Association; 2012.

40. Giles-Corti B, Donovan RJ. Socioeconomic status differences in recreational physical activity levels and real and perceived access to a supportive physical environment. Prev Med. 2002 Dec;35(6):601-11.

41. Fair society, healthy lives: the Marmot review. London: Marmot Review; 2010

42. Fisher BD, Richardson S, Hosler AS. Reliability test of an established pedestrian environment audit in rural settings. Am J Health Promot. 2010 Nov-Dec;25(2):134-7.

43. Reynolds CC, Harris MA, Teschke K, Cripton PA, Winters M. The impact of transportation infrastructure on bicycling injuries and crashes: a review of the literature. Environ Health. 2009 Oct 21;8:47. doi: 10.1186/1476069X-8-47.

44. Sekot A, Brázdová Z. Physical activity and nutrition as the social factors influencing the epidemic of obesity. Studia Sportiva, Masaryk University, Brno. 2008;2(1):112-25. (In Czech.)

45. Cerin E, Saelens BE, Sallis JF, Frank LD. Neighborhood Environment Walkability Scale: validity and development of a short form. Med Sci Sports Exerc. 2006 Sep;38(9):1682-91. 